\title{
Interactive Intranet Portal for effective Management in Tertiary Institution
}

\author{
Idogho O. Philipa \\ Department of Office Technology \\ and Management \\ Auchi Polytechnic, Auchi \\ Edo State, Nigeria
}

\author{
Akpado Kenneth \\ Department of Electronics and \\ Computer Engineering \\ Nnamdi Azikiwe University \\ Anambra State Nigeria
}

\author{
James Agajo \\ Electrical/ Electronics Dept. \\ Auchi Polytechnic, Auchi \\ Edo State, Nigeria
}

\begin{abstract}
Interactive Intranet Portal for effective management in Tertiary Institution is an enhanced and interactive method of managing and processing key issues in Tertiary Institution, Problems of result processing, tuition fee payment, library resources management are analyzed in this work. An interface was generated to handle this problem; the software is an interactive one. Several modules are involved in the paper, like: LIBRARY CONSOLE, ADMIN, STAFF, COURSE REGISTRATION, CHECKING OF RESULTS and E-NEWS modules. The server computer shall run the portal as well as OPEN SOURCE Apache Web Server, MySQL Community Edition RDBMS and PHP engine and shall be accessible by client computers on the intranet via thin-client browser such as Microsoft Internet Explorer or Mozilla Firefox. It shall be accessible through a well-secured authentication system. This Project will be developed using OPEN SOURCE technologies such XAMMP developed from WAMP (Windows Apache MySQL and PHP)
\end{abstract}

Keywords- Portal; Database; webA; MYSQL; Intranet; Admin.

\section{INTRODUCTION}

Interactive intranet portal for effective management in tertiary institution seeks to address the Problems arising from result processing, tuition fee payment, library resources management are analyzed in this work. An interface was generated to handle this problem, the software is an interactive one. An intranet is a network inside an organization that uses internet technologies (such as web browsers and servers, TCP/IP networks protocols, HTML hyper media document publishing and databases, etc) to provide an intranet-like environment with the organization for information sharing, communications, collaboration, and the support of business processes. An intranet is protected by security measures such as passwords, encryption, and firewalls, and thus can be accessed by authorized users through the intranet. Secure intranets are now the fastest-growing segment of the internet because they are less expensive to build and manage than private networks based on proprietary protocols.

Internets appeared in the mid-1990s and were perceived as the answer to the need for the integration of existing information systems into organizations. Despite the fact that has been extensive research regarding implementation, development processes, policies, standardization vs. creativity and so forth, the potentiality of intranets has not been fully exploited. Intranets offer many advantages in the form of working networks that support and enables empowered employees to participate in the development of the organization, to enable the measurement of essential functions and to monitor industries conditions and find suitable functions that support doing work.[1]

\section{BACKGROUND}

On our Institution like many other universities there is an intense need for communication and co-operation between the administrational staff and department. This is because most of the department resources like student course registration, Result management, staff management and student management have to be managed partly by one or the other group, different resources for different reasons.

\section{OBJeCTIVES}

The main objective of this project is to develop on intranet portal software that will adequately manage records

\section{A. Benefits}

1. Enable the library to keep inventory of all books

2. Keep track of borrowed books

3. Save information of all student id cards

4. Show student detail and books borrowed by these students

5. Provide easy collation of students information for clearance

6. Connect with oxford university library for additional materials

7. Web based access for e-books, papers, journals and students projects which promote Auchi Polytectnic worldwide via the internet.

8. Access journals and papers from Oxford University press.

9. A computerized easy and fast clearance process in the library

\section{B. Justification}

$>$ Need for efficient, effective and adequate management of students records[2] 


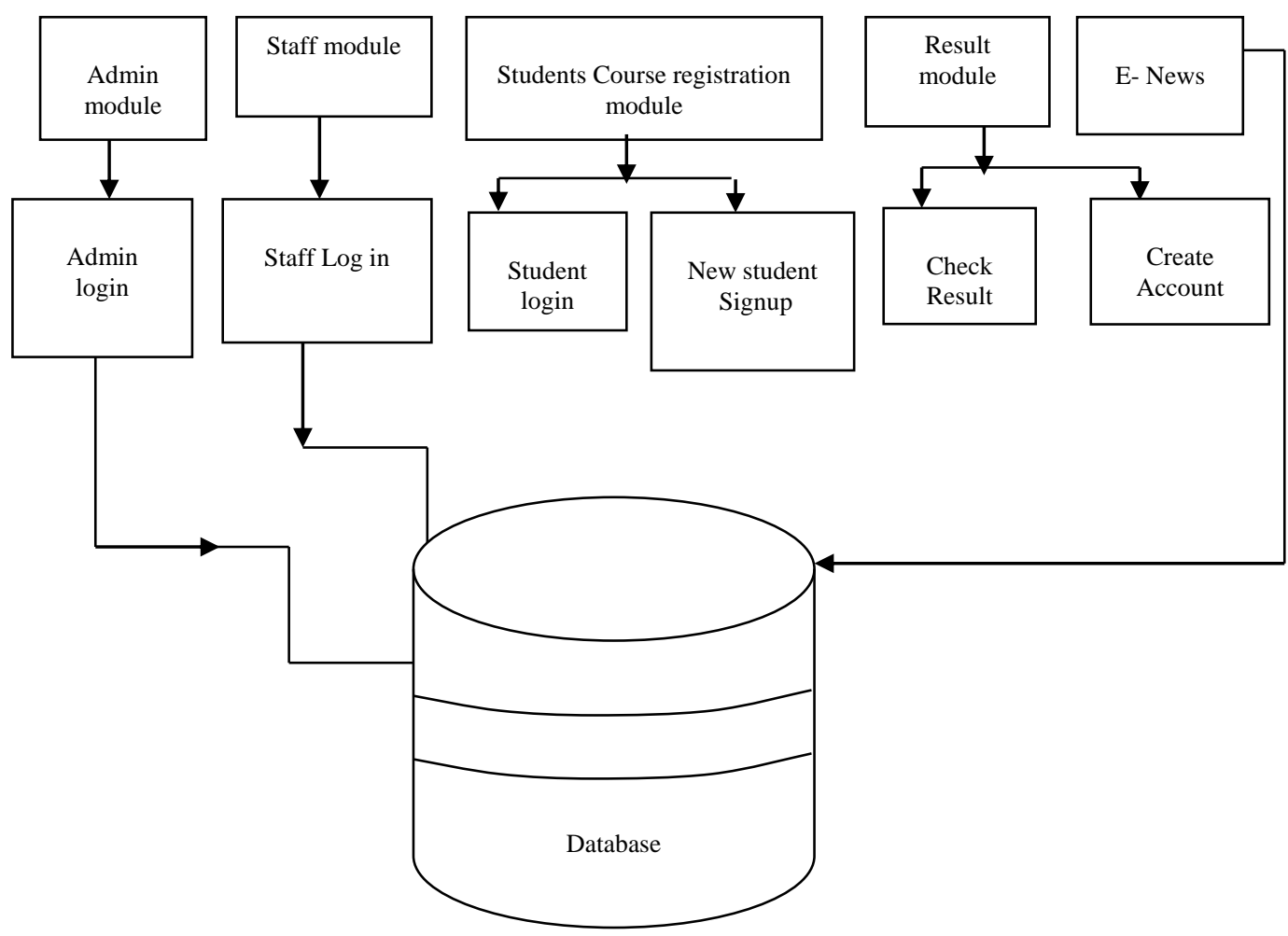

Figure 1 BLOCK DIAGRAM OF PORTAL

Need for adequate protection and security of vital information

Providing academics the ability to manage and communicate more effectively with students data.

$>$ Helping academics spend less time on processing students data

$>$ Need for easy and past means of information dissemination within the department

\section{Methodology}

Being a web-based portal, first the web development is determined using an open sources platform that will be more flexible and have lower cost due to free licensing.

Dreamweaver: This is a unique tool expressly designed for the development and optimization of web pages. All the coding in this project is done in the code view of the Dreamweaver.

Hypertext preprocessor (PHP): PHP is the web development language written by and for web developers .PHP is a server-side scripting language, which can be embedded in the HTML. In this project PHP is used to write all the forms script codes which made the software very interactive and more dynamic.

MYSQL: This is an open source, SQL Relational Database Management System (RDBMS) that is free for many uses. MYSQL is used for database management in this project.

\section{CORPORATE PORTAL DEFINITIONS}

Figure 1 show a block diagram describing various stages in the portal, a portal was referred to as search engine, whose main goal was to facilitate access to information contained in documents spread throughout internet. Initially, search engines enabled internet users to locate documents with the use of Boolean operators or associative links between web pages. To reduce even more the searching time and to help inexperienced users, some search engines have included categories, that is, they started to filter sites and sports, metrology, tourism, finance, news, culture etc. The succeeding steps were the integration of other functions, such as virtual communities and real time chats; the ability to personalize search engine interfaces (my yahoo, my Excite, etc); and to access specialized and commercial contents. This new concept of search engine is now called a portal.

\section{MAJOR CHARACTERISTICS OF A CORPORATE PORTAL}

Since corporate portals integrate some well-know technologies, such as intelligence business tools, document management, office automation, groupware, data warehouse, and intranet, some suppliers of products on these areas have also positioned themselves as corporate portal vendors. At the same time, small companies have viewed the great market opportunity of corporate portals and have announced new portal products. Besides, some big computers companies have established technical and/or commercial alliance to provide joint solutions and to suit specific needs of their customers. Therefore, the solution of a particular corporate portal, amongst all products available on the market today, is not an easy task. These are some of the characteristics of corporate portal.

* The ability to manage the information life cycle, establishing storage hierarchical levels and discarding necessary 
* The ability to locate experts in the organization, in accordance with the type of knowledge demanded for a particular task

* The ability to satisfy the information needs of all types of corporate users.

* The possibility of information exchange among customers, employees, suppliers and resellers, providing an information infrastructure suitable for electronic commerce.

Conclusively, corporate portals, whose "ancestors" are the decision support and the management information systems, are the next step into modern design of user interfaces to corporate information. Adapting the enterprise environment to suit users' needs and optimize the interaction, distribution and management of internal and external information resources the corporate portal allow users to access corporate information in an easier and customized way, resulting, the theoretically, in reduced costs, increased, productivity and competitiveness.

\section{SySTEM DESIGN APPROACH}

\section{A. Top-Down Design}

In top-down design, the system is designed in such a way that all necessary steps needed for the realization of the design will be followed promptly starting from the known to the unknown. The first stage is the approval of the project topic/title followed by the necessary information/data gathering required for the design stage. Next is the designing stage that is the main part of the work followed by the implementation of the design work where all the required components are being applied. The testing stage where the implemented works are tested in order to determine the output of the system.[3]

\section{B. Benefits}

- To save time and reduce the stress involved in student's result processing;

- To facilitate student's result processing activities with the aid of a program to give rise to effective production of student's results with fewer human errors;

- To handle large volumes of results processing;

- To aid the management in the providing results data in time.

- To design a computerized result processing system that will minimize the amount of manual input needed in student result processing.

Such a system would help the polytechnic system in becoming more computer-friendly and technologically-inclined as staff and students could make use of it and benefit more from its numerous objectives and advantages.

Figure 2 and figure 3 shows Flow chart of student course registration Module and Flow chart of Admin module. The flow diagram represents the stages and sequence this world pass through.

\section{Structural AnAlysis}

The first point to mention is the users of the system. Different user can use the portal. The system will be analyzed in the following [4]
* Admin Module: The admin module has interface that allow the administrator to login into the system and have over roll control of the system. The Admin has to create login ID and password

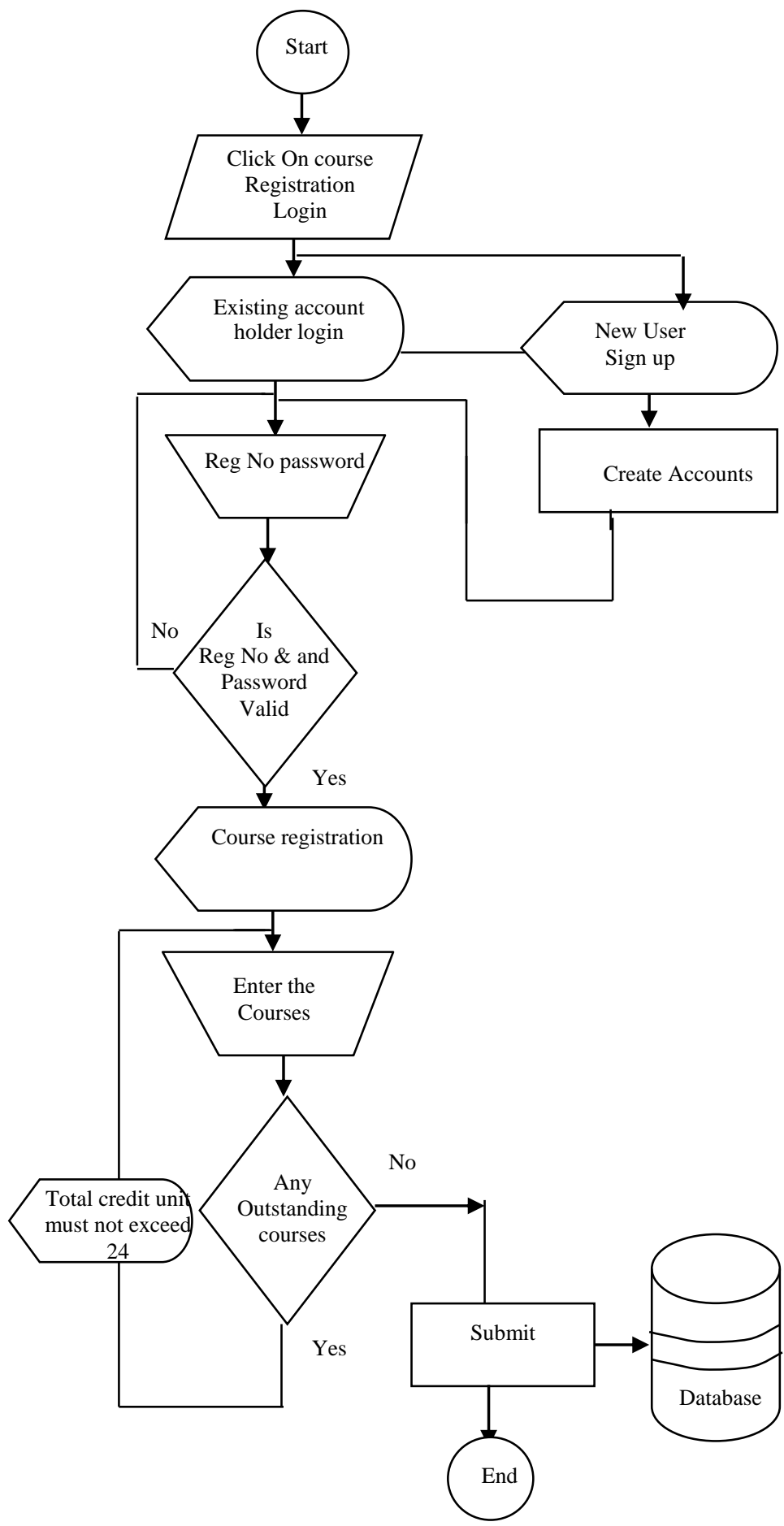

Figure 2. Flow chart of student course registration Module

to the authorized staffs. The admin decides on certain privileges like update, delete, and edit to only authorized persons. The logic flow in Admin module is represented below. 


\section{Student Course Registration Module}

This module has interface that allow students to register their courses. A new student who has not registered at all has to go through student account signup and obtain user name and password before being able to enroll to the program and select courses. In the signup step, the student is asked to fill his profile information such as his first name, last name, middle name, registration number, and gender, date of birth, email address, permanent address, phone number and educational level. The student has to login with the user ID and password obtained from signup account. The logic flow in the student course registration is represented below. [6]

\section{Result Module}

This module has interface that allow students to login into

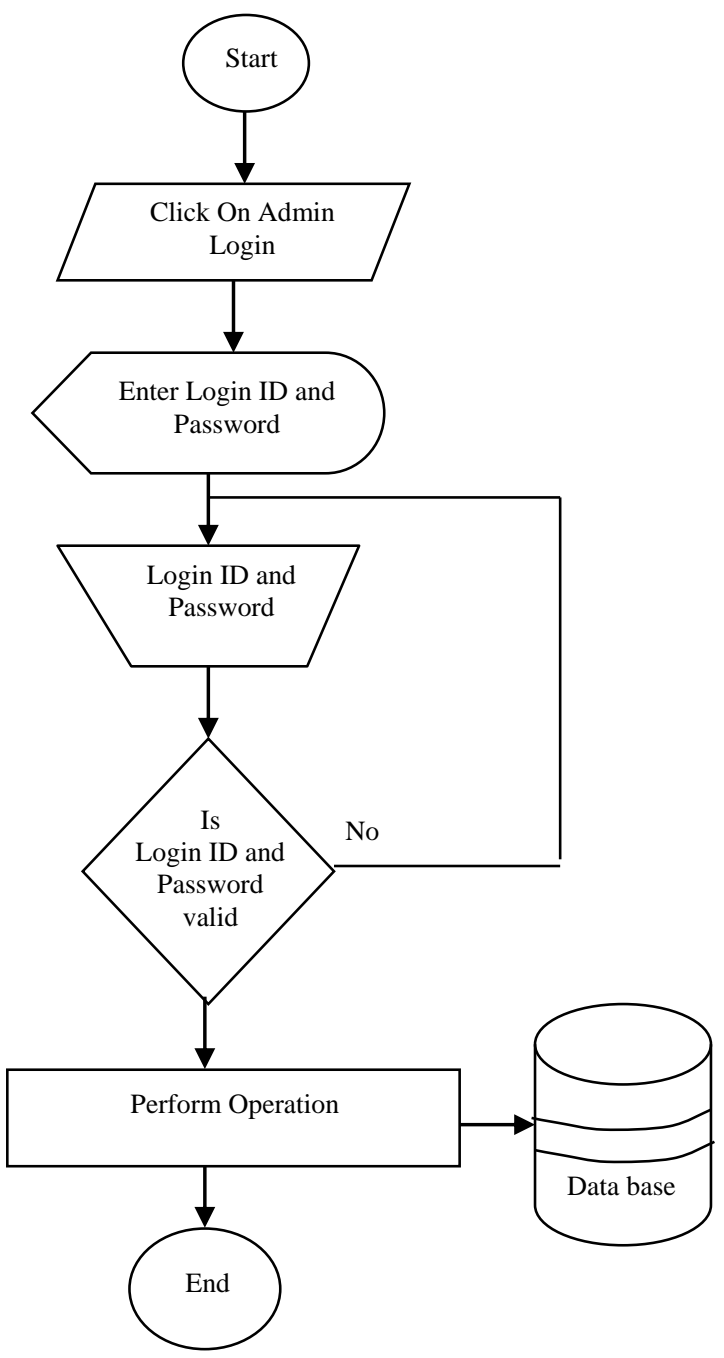

Figure 3 Flow chart of Admin module

the system, using their registration number and password. New users have to signup an account that will enable them to $\log$ in and access their result. The system uses the registration number to query the database in order to retrieve the result pointing to the registration number. The logic flow in the result module is represented below.

\section{Database Design}

The database is the long-term memory of the web database application. Relational database management system (RDBMS) was considered during the design of this database. The database structures have tables and their relationships are defined. The databases have eight (8) tables and they are related with primary and foreign keys..[7]

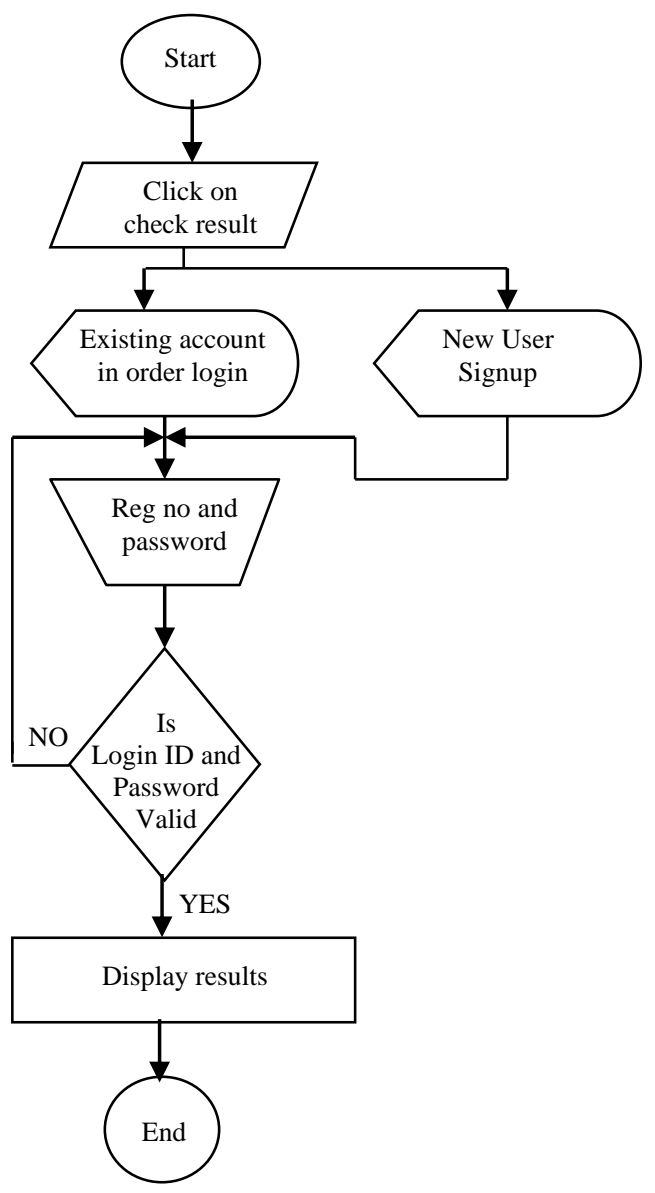

Figure 4 Flow chart of Result Modules module

1) Course table

2) Course level table

3) Exam table

4) Student table

5) Staff table

6) Semester table

7) Session table

8) Year table

9) Result table

\section{SYSTEM IMPLEMENTATION}

The system implementation was done using open source software XAMMP developed from WAMP (Window Apache, MYSQL and PHP) and integrating it with macromedia Dreamweaver installed on computer. The following and done for the implementation.[8],[9] 

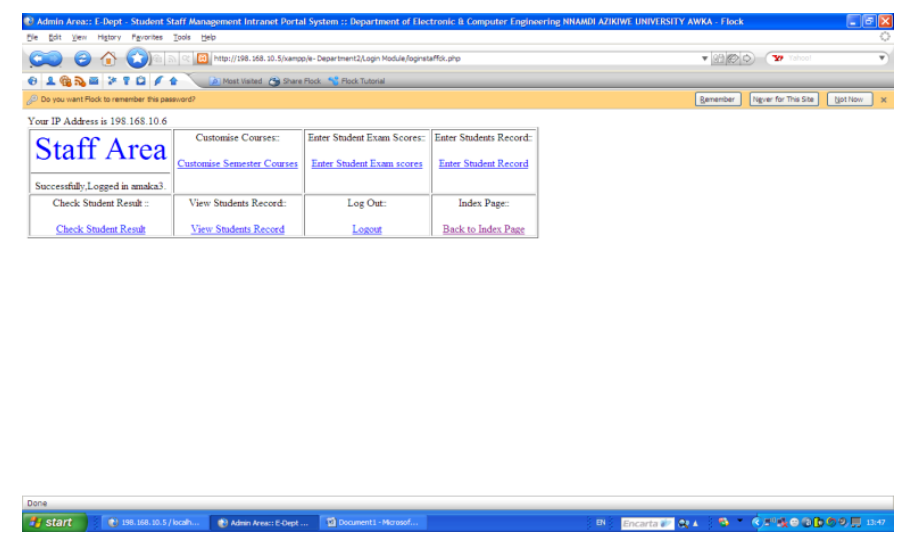

Figure 5 Proposed interface for Auchi library Management

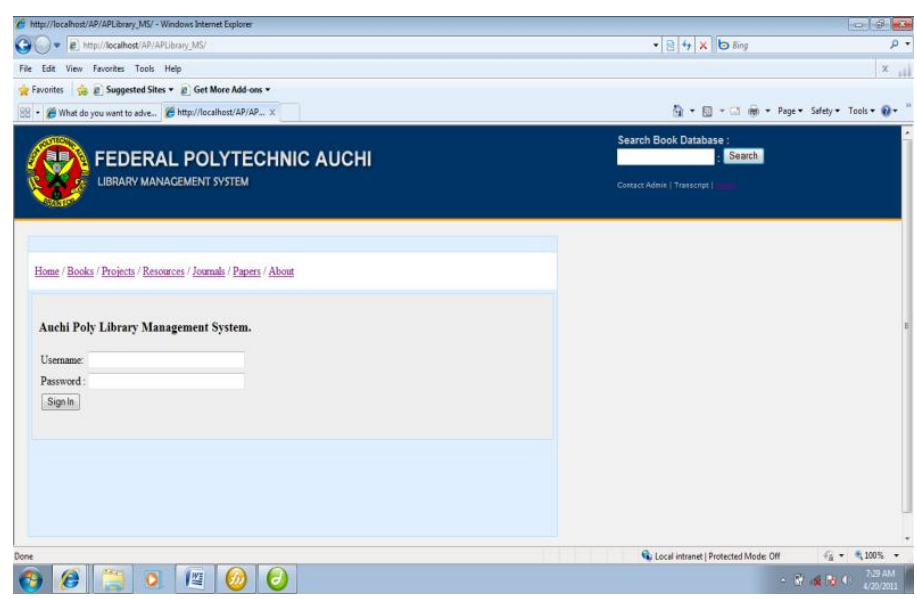

Figure 6 (SCREEN SHOT) APPLICANT STATISTICS 1

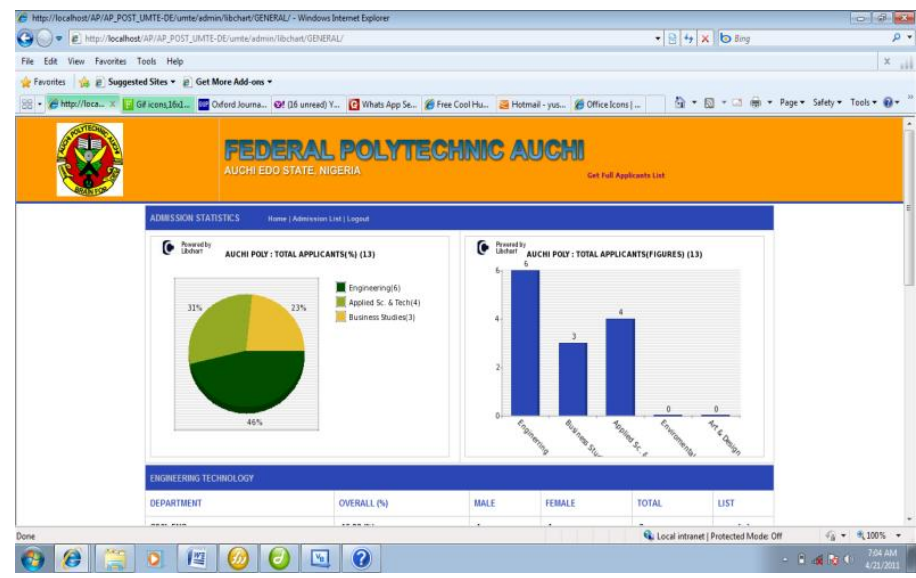

Figure 7(a) (SCREEN SHOT) APPLICANT STATISTICS 2

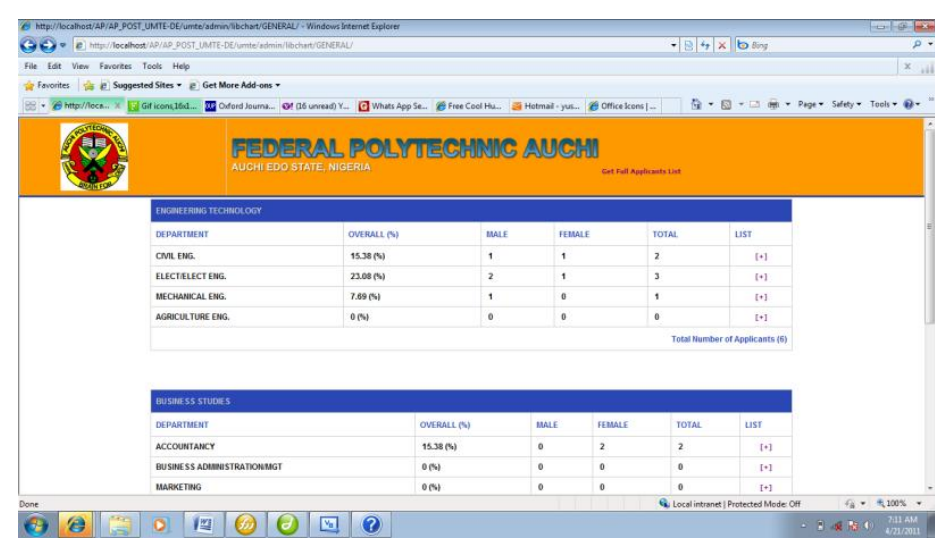

Figure. 7(b) (SCREEN SHOT) APPLICANT STATISTICS 3
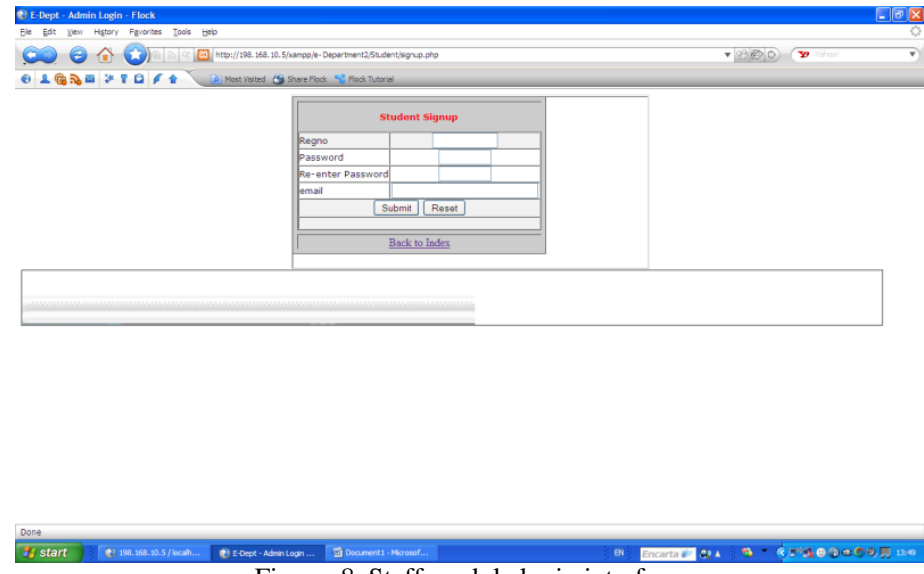

Figure. 8 Staff module login interface

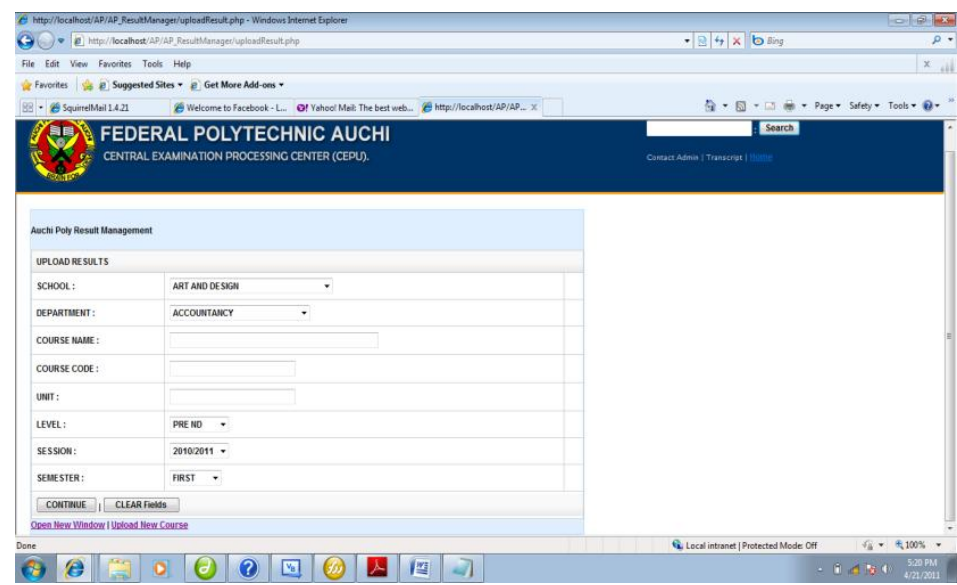

Figure 9 Student course Registration interface 


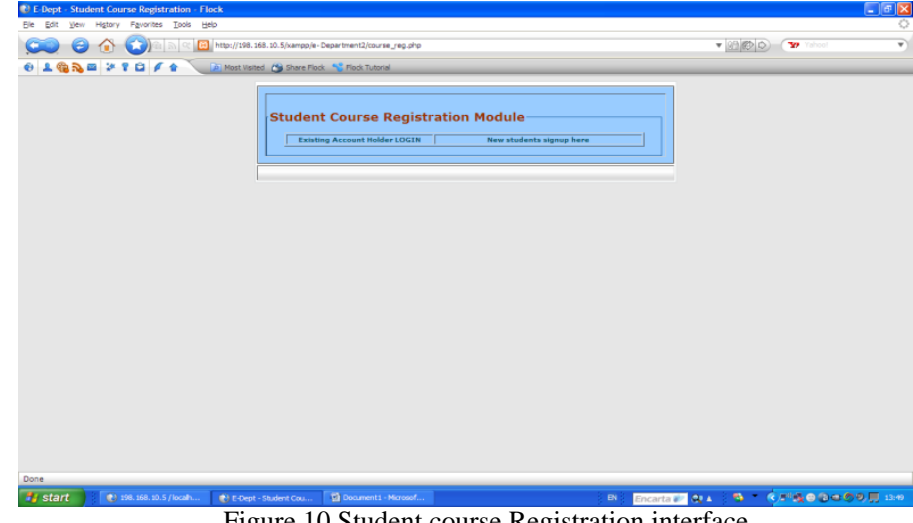

Figure 10 Student course Registration interface

1) The modules image was created using macromedia flash 8.0

2) The admin module was created by following the logic flow diagram using dream weaver 8.0

3) The staff module was also created as in figure 8

4) Student course registration / check result modules was also created

5) E-news module was created and linked to Admin module

Admin login was created and the login ID and password is also created and store in the database

Finally common database was designed for all the modules

\section{Sub Modules IMPLEMENTATION}

\section{A. Admin Module}

The following are done on implementation Admin Area was created and it has the following features

1) Customize semester courses

2) Enter student Exam scores

3) Enter student Record

4) Check student result

5) View students record

6) Logout

7) Back to Index page

8) Assign login details to staff

B. Staff Module

The following are done on Implementation

1) Obtain login ID and password from admin

2) Staff Area was created and it has the following features , see figure 8

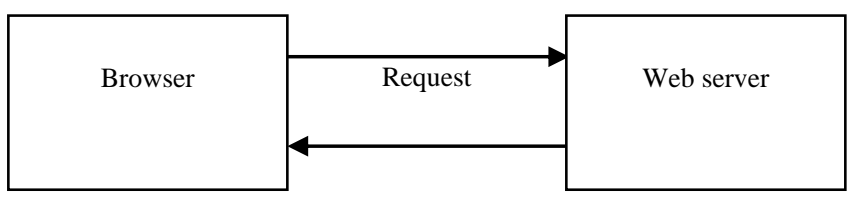

Figure 11 Student Sign up Block interface $[13,14]$
a) Customize semester courses
b) Enter student Exam scores
c) Enter student Record
d) Check student result
e) View students record
f) Logout
g) Back to Index page

\section{AUCHI Polytectnic WeB BAsed AdMission PROCESSING CENTER}

The system will help speed up admission processing within $24 \mathrm{hr}$. The proposed system will automatically categorize every applicant within their various choices and arrange them according to their performance (Jamb Score) in an ascending order. More Explanation can be provided if requested. [8]

\section{A. Student course registration}

The following are done on implementation

1) Student course registration as shown in figure. 10 have two sub modules was created which account is stored in the signup database table.

a) Existing Account Holder

2) Existing account holder login was also created

3) New student signup here was created and the data account is stored in the signup database table.

4) Existing account holder login was also created.

\section{DATABASE IMPLEMENTATION}

Implementation of the database is carried out on MYSQL 5.0 DB sever engine. The data retrieval is analyzed in the implementation phase. The basic operation of a web server is in fig 13 and 14.

A communication link is required between them. A web browser makes a request of the server. The servers send back a response. The web database implementation in this project follow a general web database structure as shown.

The basic web database architecture consists of the web browser, webserver, scripting engine and database server

The following stages are involved in data retrieval from the database

1) A user's web browser issues an HTTP request for a particular web page

2) The web server receives the request for the page, retrieves the files, and passes it to the PHP engine for processing

3) The PHP engine begins parsing the script. Inside the script is command to connect to the database and execute a query. PHP opens a connection to the MYSQL server and sends on the appropriate query.

4) The MYSQL server receives the database query, processes it and sends the results back to the PHP engine the database as shown below. 


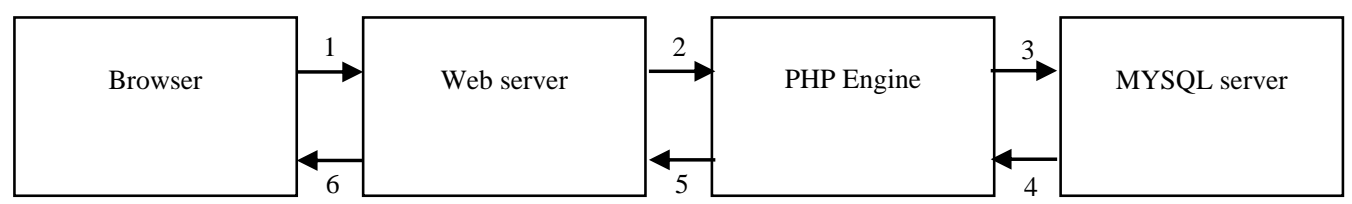

Figure 12 Student Enhanced Sign up Block interface [15,16]

\section{A. Database entity relationship model}

This is the relationship model in MYSQL database as shown in the figure 15

\section{a) Creating Database table}

All the database tables in my design was created in MYSQL by writing the SQL requires save in the root of my web server called SQL.Main. Proper SQL command was used to insert it into

\section{System Testing ANd Evaluation}

\section{A. Test Plan}

In testing this work, one should adopt, first the bottom-up approach to test the various modules before finally testing the complete system with the control program as was done in this work.

Furthermore, ones main concerned was the fact that the system should meets its functional and requirements.

\section{B. Testing the Admin Module Interface}

The module was really tested with the xampp server user Interface in figure 16. The admin was tested with the valid login ID and password that allow the admin into database and the admin area was display on the interface.

\section{Testing the Staff Module Interface}

This module was really tested with the xampp server user interface. The login ID and password obtained from admin was used to test the staff module and it was successful

\section{Testing the Student Course Registration Module Interface}

This module was really tested with the xampp server user interface. The module was tested with the login ID and password obtained by student signup account. It interacted with the database

\section{E. Testing the Check Result Module Interface}

This module was really tested with the xampp server user interface.

The module was also tested with the login and password obtained from student check result signup account. The testing was successful.

\section{F. Software Testing and Debugging}

The program development was carried out in modules using dreamweaver8.0 connected to xampp server containing Apache, MYSQL and PHP. The first task was to write all the PHP codes in Dreamweaver and save it in root of my server. Next was to check if the Apache server is running which acts as the web server and if it connected to MYSQL database.

Finally, all the modules were linked into the database to check if they are all running.

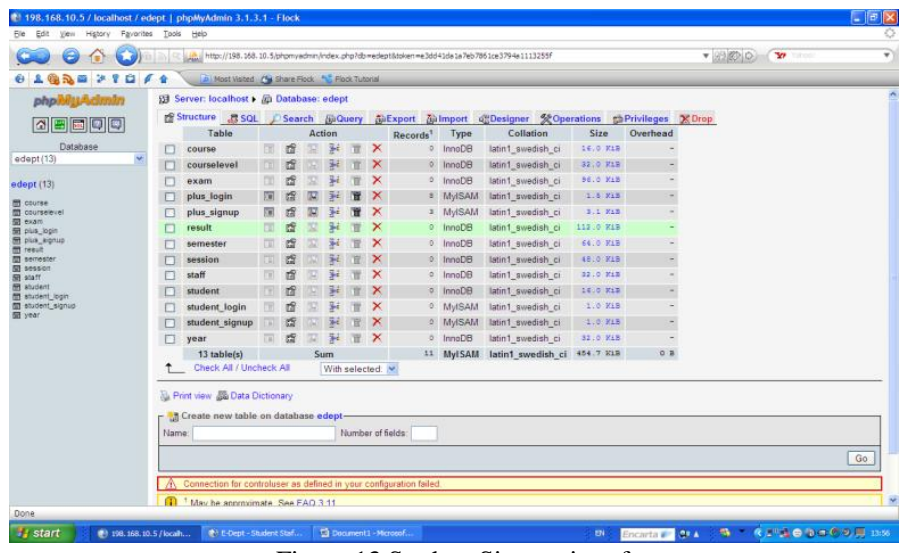

Figure 13 Student Sign up interface

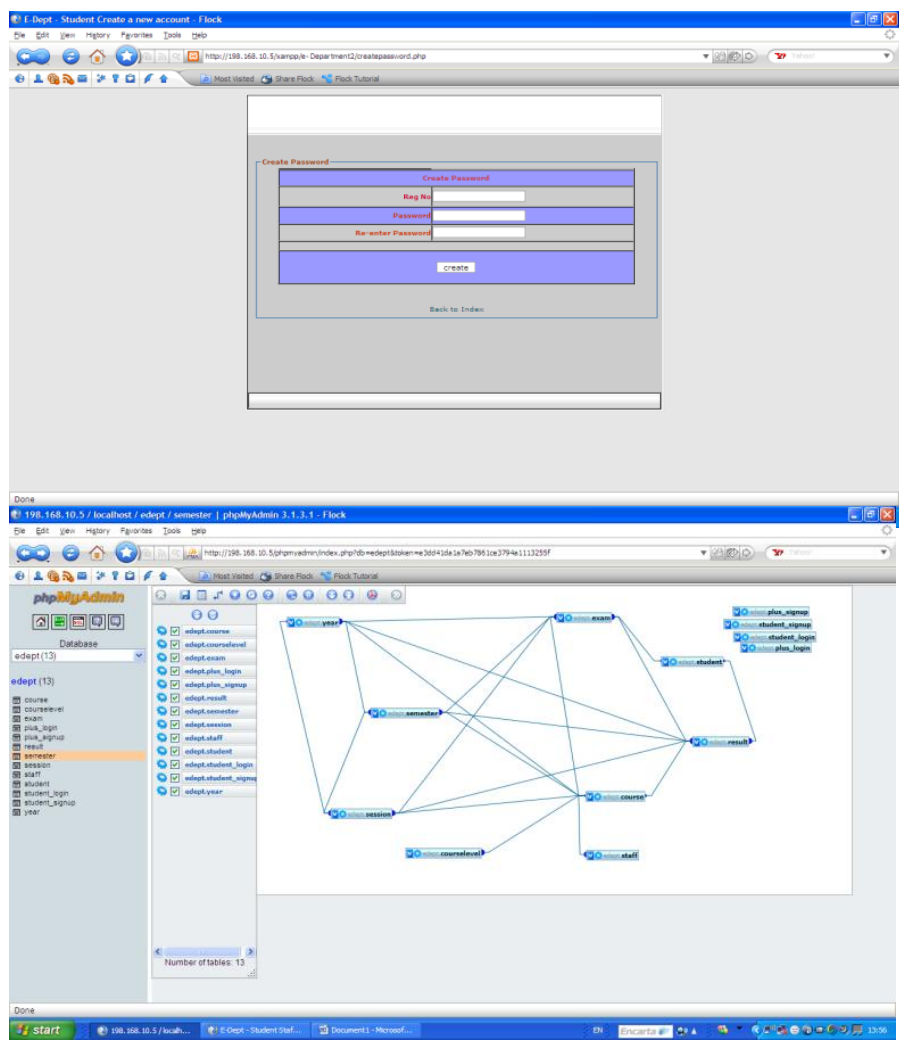

Figure. 14 :Client/Server relationship between and server

Figure. 15 Database entity relationship model interface

\section{ACTUAL VS EXPECTED RESUlTS}

During random testing of all the modules some errors came up and I discovered that it was not inserting data into the database. 
TABLE 1. ACTUAL ReSUlt VS. EXPECTED RESUlt

\begin{tabular}{|l|l|}
\hline ACTUAL RESULT & EXPECTED RESULT \\
\hline $\begin{array}{l}\text { It does not insert data into the } \\
\text { database. }\end{array}$ & $\begin{array}{l}\text { Expected to insert data into the } \\
\text { database. }\end{array}$ \\
\hline Could not execute SQL queries. & It is supposed to execute SQL queries. \\
\hline
\end{tabular}

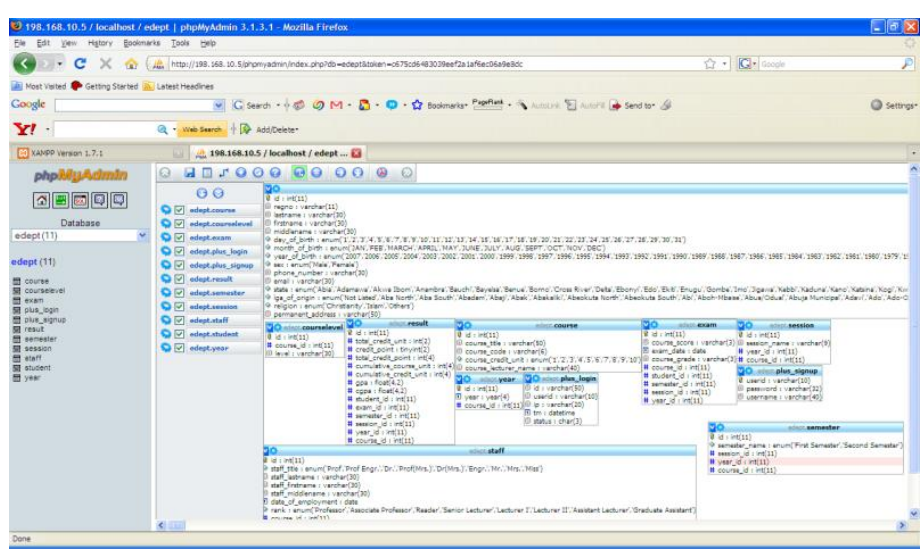

Figure. 16 Database tables interface

\section{Performance Evaluation}

The performance of the Results did not meet the actual design of this project. It is expected that the project can be continued upon after the defense to meet the required design of this project.

The proliferation of digital information resources and electronic databases challenges libraries and demands that libraries develop new mechanisms to facilitate and better inform user selection of electronic databases and search tools.[11,12]

\section{CONCLUSION}

The fundamental idea of intranet portal-based designs is to reduce the amount time spent in data processing. Companies and organizations with intranet portal have attracted much stock market investors interest because portals are viewed as able to command a large audience.

Finally, intranet portal bring vast information and services resources available from many sources to many users within the same organization in an effective manner.

\section{REFERENCES}

[1] Horton Jr., F., "Infotrends", Prentice Hall $2^{\text {nd }}$ edition, pp. 185-191, 1996.

[2] Oliveira, D., São Paulo: Atlas, IEICE Trans.Commun., pp 123-144, 1996.

[3] Cronin, B., \& Davenport, E., "Elements of Information management". New Jersey: Scarecrow Press, 1991.

[4] Taylor, A., \& Farrell, S., "Information management in context". Aslib proceedings, 44(9), pp. 319-322, 1992.

[5] Butcher, D., \& Rowley, J., "The 7 Rs of Information management" Managing Information, 5(3), pp. 34-36, 1998.

[6] Shilakes, C. C., \& Tylman, J., "Enterprise Information portals". New York: Merril Lynch, (November 16). [online], October 1999.

[7] Collins, D., "Data warehouses, enterprise in information portal, and the
SmartMart meta directory", Information Builders Systems Journal, 12(2), pp. 53-61, 1999.

[8] Murray, G., "The Portal in the desktop". Intraspect, (May/June)[http://archives.grouping computing.com//index.cfm?fuseaction=viewarticle\&contentID=166] . October 1999.

[9] Viador, "Enterprise Information portals: Realizing the vision of ourfingertips".January)[http://www.viador.com/pdfs/EIP_white_paper _1_99.pdf]. April 2000.

[10] White, C., "Enterprise information portal requirements". Morgan Hill,CA:DatabaseaAssociatesinternational,(January)[http://www.decisio n processing.com/papers/eip2.doc]. April 2000.

[11] Wei Ma, Journal of the American Society for Information Science and Technology archive Volume 53 Issue 7, John Wiley \& Sons, Inc. New York, NY, USA July 2002

[12] Dutta S.B.Wierenga and A. Dalebout, Designing Management support systems using an integrative perspective "Communication of ACM Vol. 40 No 6.1997 june.

[13] Mintzberg H., et al, The strategic Portal process, $4^{\text {th }}$. Edition upper saddle River, NJ: Prentice Hall (2002).

[14] Mora M. , Management and organizational issues(information Resources management journal special issue October/December 2002.

[15] McNurlin B.C and R.H. Information system Management, $7^{\text {th }}$. Edition upper saddle River Prentice Hall.(2005 February)

[16] Joch A.(2005,January/February)"Eye on Information" Oracle Magazine (2005,January/February)

\section{ABOUT THE AUTHORS}

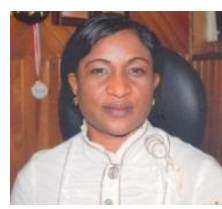

Dr. (Mrs.)Philipa Omamhe Idogho, a scholar, received the Ph.D in Educational Administration from Ambrose Alli University Ekpoma, and a Master Degree in educational Management from University of Benin. With over 28 years of teaching/research experience, she is currently the Rector of a first generation Federal Polytechnic in Nigeria (Auchi Polytechnic, Auchi). She has more than 50 papers in National/International Conferences/Journals to her credit. She is a fellow, Nigeria Institute of Management, Institute of Administrative Management of Nigeria and member, Association of Business Educators of Nigeria, Association for Encouraging Qualitative Education in Nigeria, and other recognized professional organizations. Outside her academic life, she runs a Non-governmental Organisation (NGO) known as Women Enhancement Organization. It is a charitable, non-profit making, nonpartisan and non-religious organization which works in three thematic areas of gender works, HIV/AIDS and literacy education for rural women and vulnerable children.

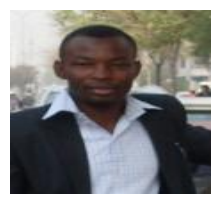

Engr. James Agajo is into a Ph.D Programme in the field of Electronic and Computer Engineering, He has a Master's Degree in Electronic and Telecommunication Engineering from Nnamdi Azikiwe University Awka Anambra State, and also possesses a Bachelor degree in Electronics and Computer Engineering from the Federal University of Technology Minna Nigeria. His interest is in intelligent system development with a high flare for Engineering and Scientific research. He has Designed and implemented the most resent computer controlled robotic arm with a working grip mechanism 2006 which was aired on a national television, he has carried out work on using blue tooth technology to communicate with microcontroller. Has also worked on thumb print technology to develop high tech security systems with many more $\mathrm{He}$ is presently on secondment with UNESCO TVE as a supervisor and a resource person. James is presently a member of the following association with the Nigeria Society of Engineers(NSE), International Association of Engineers(IAENG) UK, REAGON, MIRDA,MIJICTE.

Engr. Kenneth Akpado is a Ph.D Research student, he holds an M. Eng B. Eng. in Electronics and Computer Engineering, a Member of IAENG,MNSE and COREN, he is presently a Lecturer in the Department of Electrical Electronics Engineering in Nnamdi Azikiwe University Awka Anambra State, Nigeria. 